\title{
PATTERN OF FACIAL BONE FRACTURES IN ROAD TRAFFIC ACCIDENTS RIDING ON TWO WHEELERS IN A TERTIARY HOSPITAL IN BANGALORE, INDIA
}

\section{Plastic Surgery}

Dr Kumaraswamy Institutional mailing address- department of plastic surgery Ramaiah Medical College Mohan Kumar*

\section{ABSTRACT}

The injury to the face is second most common in cases with road traffic accidents in patients on two wheelers. This adds to physical, social, emotional, economical burden and also psychological problems to the patient. It is a retrospective case record study of patients who had come to casualty with Road traffic accidents and were riding a two wheeler. 89 patients were selected with facial bone fractures and analyzed. Out of 89 patients $19 \%$ patients had single bone fracture and $67 \%$ had multiple bone fractures. Most common fractures were maxilla and nasoethmoid fractures. Conclusion- wearing full helmets can decrease the severity of these injuries. Awareness about wearing full helmets should increase.

\section{KEYWORDS}

facial bone fractures, two wheeler riders, road traffic accident, helmet,

\section{INTRODUCTION}

Craniofacial injury is very common type of injury attending the casualty. Road traffic accidents are the most common cause of facial injuries $[1,2,3]$. The people moving on two wheelers are the most common people attending the casualty with facial injuries $[1,3]$. The reasons for RTA are varied depending on the social, cultural, legislations and their incidence and patterns differ as per the region. The common reasons attributed to road traffic accidents are driver related issues like over speeding, not obeying traffic rules, driving under the influence of alcohol or drugs, bad roads, bad light, slippery roads, unsafe road infrastructure, unfit vehicles being used with bad tyres or bad brakes, distraction while driving like using mobile phones, inadequate enforcement of traffic laws, etc.[4,5]. The number of two wheelers in India is more than the 4 wheelers; hence we find Road traffic accidents with two wheelers more common. Use of helmet in Karnataka by both drivers and pillion riders of two wheelers is compulsory by law, but the validity of the two wheeler riders reporting of using a helmet is more than observed[6,7]. The situation is worse in rural areas and semi urban areas, where enforcement of traffic laws is weak, two wheeler users do not use helmet. So we undertook the study to know the pattern of craniofacial injuries seen in two wheeler riders. The morbidity of the road traffic accidents and the mortality is high. In India, where more than $70 \%$ of health care is catered by the private sector and low insurance cover brings a huge financial burden. It is important to study the epidemiology to device preventive measures [8].

Aim- To know the pattern of craniofacial bone injury in patients riding two-wheeler

- To suggest prevention methods

\section{Materials and methods}

The retrospective study was conducted in a single, tertiary care hospital in Bangalore. All patients who came to the casualty with alleged history of Road traffic accident when riding a two wheeler were included in the study. The patients whose clinical examination did not warrant the need for facial bone $\mathrm{X}$ rays or facial bone $\mathrm{CT}$ were excluded from the study. The case records of all the included patients were studied. Their age, sex, time of injury, the facial bone X-rays and CT scans was recorded.

The age was tabulated in different age groups, male and female patient ratio was calculated, time of accident was tabulated in different groups. The patients' fractures were recorded, either as single or multiple or no fractures. If patient had multiple fractures, the fractures were recorded under cranial, orbital, nasal, maxilla, zygoma, and mandible. Percentages of each were calculated.

\section{Results}

As per our inclusion criterion, 89 patients, who visited the casualty between March 2012 to June 2017, were included in our study. Their case records were analyzed. There were 7 females and 82 males in our study. The male to female ratio was 11.7:1. (Table 1)
Table 1-shows number of male and female patients in the study

\begin{tabular}{|c|c|c|}
\hline & No of patients & Percentage of patients \\
\hline Female & $7(89)$ & $7.86 \%$ \\
\hline Male & $82(89)$ & $92.13 \%$ \\
\hline
\end{tabular}

Their age ranged from 6 years to 70 years. There were 36 patients in 21 29 age group followed by 26 patients in 30-39 age groups. There were 8 patients under 20 years and 2 patients between $60-70$ years age group. (Table 2) The average age presented to the casualty was 31.62 years

Table-2, Number of patients in each age group

\begin{tabular}{|c|c|c|}
\hline Age group & Number of patients & Percentage of patients \\
\hline Less than 10 & 02 & $2.2 \%$ \\
\hline $11-20$ & 06 & $6.7 \%$ \\
\hline $21-29$ years & 36 & $40.4 \%$ \\
\hline $30-39$ years & 26 & $29.2 \%$ \\
\hline $40-49$ years & 07 & $7.8 \%$ \\
\hline $50-59$ years & 10 & $11.2 \%$ \\
\hline $60-69$ years & 01 & $1.2 \%$ \\
\hline 70 and above & 01 & $1.2 \%$ \\
\hline
\end{tabular}

The time of accidents was recorded (Table 3 ). It was more common between $3 \mathrm{pm}$ to $9 \mathrm{pm}$. About $38 \%$ of the RTA happened in this time. There were 10 patients under the influence of alcohol

Table 3- Time of accident and the number of patients involved.

\begin{tabular}{|c|c|c|}
\hline Time of accident & No of patients & Percentage \\
\hline $00-6 \mathrm{am}$ & 4 & $4.5 \%$ \\
\hline $6 \mathrm{am}-3 \mathrm{pm}$ & 33 & $37 \%$ \\
\hline 3pm-9pm & 34 & $38.2 \%$ \\
\hline 9pm-12midnight & 18 & $20.2 \%$ \\
\hline
\end{tabular}

The facial bone X- Rays and CT scans were noted and the recorded as single fracture or multiple fractures (Table 4). The fractures were recorded under cranial, orbital, nasal, maxilla, zygoma, and mandible. 5 patients had no facial bone fractures. 17 patients had single bone fractures and 67 had multiple bone fractures.

Table 4- Table showing number of patients with fractures, single, multiple or no fracture.

\begin{tabular}{|c|c|c|}
\hline No fractures & 5 & $5.6 \%$ \\
\hline Single bone fractures & 17 & $19.1 \%$ \\
\hline Multiple bone fractures & 67 & $75.2 \%$ \\
\hline
\end{tabular}

The fractures were tabulated under cranial, orbital, nasoethmoid, maxilla, zygoma, mandible (table 5). The cranial bone fractures included frontal bones, temporal, parietal bones, mastoid, and occipital bones. The nasoethmoid included nasal bones, ethmoid bone and ethmoid sinuses. The maxilla included lefort I, II, III fractures. The orbital fracture includes medial wall, lateral wall, roof and floor. The zygoma included body and arch. The mandible included all parts of mandible. 
Table 5- Number of patients with different types of fractures.

\begin{tabular}{|c|c|c|}
\hline Anatomic region & $\begin{array}{c}\text { Number of patients } \\
\text { with fractures }\end{array}$ & Percentage \\
\hline Cranial & 33 & $37 \%$ \\
\hline Orbital & 42 & $47.1 \%$ \\
\hline Nasoethmoid & 60 & $67.4 \%$ \\
\hline Maxilla & 64 & $71.9 \%$ \\
\hline Zygoma & 33 & $37 \%$ \\
\hline Mandible & 19 & $21.3 \%$ \\
\hline
\end{tabular}

In our series the maxilla and the nasoethmoid were the commonest with $71.9 \%$ and $67.4 \%$. of the fractures. Mandible was the least common bone involved. 4 patients out of 10 patients under 20 years of age, had maxilla fracture which was commonest under 20 years age group.

\section{DISCUSSION}

Facial injury in patients with Road traffic accidents where two wheelers are involved is very common. The mortality because of two wheeler accidents has decreased with the use of helmets. The injuries what is seen can be soft tissue injuries and facial bone fractures. Our study is on the facial bone fractures. The patients are a mix of semi urban and urban population.

In our study, 20-29 years of age patients, were the most common attending with two wheeler accidents with facial bone fractures. The average age was 31.6 years in our study. This is consistent with the other studies both Indian and outside countries. Venugopal et al in their study showed that 24.3 years was the average age of patients with facial bone fractures [3]. Zargar et al in 2004 have documented in his study from Tehran that 11-30 years was the most common age group [2]. Ravikumar et al, in 2017 has documented that 21-30 years was the most common age group1. Most of the studies with predominantly patients with RTA as the etiology show that 3rd and 4th decade are the most commonly involved [910,11]. This is age is more prone probably because of the risk taking tendency in this age group. The numbers of users of two wheelers are more in this age group.

The study by Prasad et al [12] showed that $80 \%$ of the patients were males in all cases of craniofacial trauma and study by Al Ahmed et al [13] showed male to female ratio of 11:1 and MG Venugopal et al shows males to female ratio of 21:1. It is similar to our series, as the number of RTA patients in his study constitutes about $87 \%$ [3]. Our series had $92 \%$ of males probably because; we have included only patients with RTA. Our study shows that the ratio is 11.7:1. All studies have shown more of male preponderance. This may be attributed to the number of male using two wheelers out number female users.

Road traffic accidents are more common between $3 \mathrm{pm}$ to $9 \mathrm{pm}$ [4]. Our study also showed $38 \%$ of the patients had RTA between these times. This was followed by $6 \mathrm{am}$ to $3 \mathrm{pm}$. This can be attributed to the density of vehicles on the road and the rush hour traffic. Between $9 \mathrm{pm}$ to 12 midnight the number was 18 . This may be because of low light, tiredness, driving under the influence of alcohol.

Table 6- comparison of various studies with our study.

\begin{tabular}{|c|c|c|c|c|c|c|c|}
\hline Study & $\begin{array}{c}\mathrm{RTA}(2 \mathrm{w} \\
\text { heeler) }\end{array}$ & $\begin{array}{l}\text { Nasoeth } \\
\text { moid }\end{array}$ & $\begin{array}{c}\text { Mandib } \\
\text { le }\end{array}$ & maxilla & \begin{tabular}{|c|} 
zygo \\
ma
\end{tabular} & orbit & Cranial \\
\hline $\begin{array}{l}\text { Our } \\
\text { study }\end{array}$ & 89 of 89 & $67.4 \%$ & $21.3 \%$ & $71.9 \%$ & $37 \%$ & $\begin{array}{c}47.1 \\
\%\end{array}$ & $37 \%$ \\
\hline $\begin{array}{c}\text { Hassan et } \\
\text { al } 2011\end{array}$ & $45 \%$ & $79 \%$ & $11 \%$ & $5 \%$ & NA & & $\%$ \\
\hline $\begin{array}{c}\text { Prasad et } \\
\text { al } 2009\end{array}$ & $54 \%$ & NA & $36 \%$ & $15 \%$ & $21 \%$ & NA & NA \\
\hline \begin{tabular}{|c|} 
Pranav \\
Kapoor \\
et al 2012
\end{tabular} & $\begin{array}{c}404 \text { of } \\
1000\end{array}$ & & $63 \%$ & \multicolumn{4}{|c|}{$\begin{array}{l}\text { Pan facial 16\% } \\
\text { Mid facial 22\% }\end{array}$} \\
\hline \begin{tabular}{|c|} 
Ravikum \\
ar et al \\
2017
\end{tabular} & $\begin{array}{c}536 \text { of } \\
626 \\
(85.62 \%)\end{array}$ & \begin{tabular}{|c|} 
Nasal- \\
$7.25 \%$ \\
Nasoeth \\
moid- \\
$1.08 \%$
\end{tabular} & $37 \%$ & $\begin{array}{c}\text { Lefort } \\
\text { I( } 31.88 \%) \\
\text { Lefort } \\
\text { II }(21.38 \%) \\
\text { Lefort } \\
\text { III }(5.79 \%)\end{array}$ & $36.2 \%$ & NA & NA \\
\hline
\end{tabular}

\begin{tabular}{|c|c|c|c|c|c|c|c|}
\hline Rajsheka & 360 of & Nasal- & 360 of & 278 of 869 & 231 of & & 31 \\
r et al & 638 & 17 of & 869 & & 869 & & \\
& & 869 & & & & & \\
& & $\begin{array}{c}\text { Nasoeth } \\
\text { moid- } \\
2015\end{array}$ & & & & & \\
& & 869 & & & & & \\
\hline
\end{tabular}

Our study showed nasoethmoid and maxilla which was more than 50\% fractured. This was consistent with Hassan et al [13] who had 79\%. In his series he had $45 \%$ of his cases due to RTA. The maxilla fracture is less than $50 \%$ in majority of the studies. Orbital bone fractures are $47.1 \%$ in our study, which is more when compared to other studies. Mandible fractures in our study are $21 \%$ which is comparable to other studies. When compared to Pranav et al [14], our study does not match with in mandible fracture which is $63 \%$ and panfacial fracture which is $16 \%$. In our study it was $21 \%$ of mandible fractures and $67 \%$ of multiple facial bone fractures. Kraus et al [15] in their study showed $70 \%$ cranial fractures, we had $37 \%$. This could be because; he has included all patients who had facial bone fractures and ours is only with two wheeler patients. Wearing of helmets is compulsory by law in our region. Both half helmet and full helmet protect from cranial bone fractures. Rajashekar et al [16] had 31\% cranial bone fractures and our study showed $37 \%$. There is lot of variation in pattern of fractures that has been documented (Table 6) in different regions of world and India, because of different social, economic, educational levels and practices.

There are two types of helmets available, half helmet which has no protection to the chin and bat the center below the level of the eye. The full helmet has a chin protector and a visor. We could not document an authentic history of whether the patient was wearing a helmet, full helmet or half helmet. Our study shows that in two wheelers accidents, we have $71.9 \%$ of maxilla fractures, $67.4 \%$ of nasoethmoid involvement. These are thin bones and are most vulnerable when the patient falls. The patients may be wearing half helmet and would have had a frontal or lateral impact. This might have injured the nasal and the maxillary region. Considering the protection a full helmet provides, probably the severity could have been decreased.

Road accidents were highest involving the two wheelers which was $28.8 \%$ of all the road traffic accidents in 2015[4]. Road traffic accidents are growing concern since it has been increasing every year and as of 2015 statistics it is 40 per lakh population [4]. There are other injuries which can happen with two wheeler accidents like peripheral bone fractures, abdomen and chest injuries. Some may be life threatening and some are morbid.

The facial injuries, including head injuries are the most common next to extremity injuries in two wheeler accidents [17]. The head and neck injuries can be prevented by the use of helmets. The morbidity of facial injuries may give a scar, and being most visible part in human body, there is a psychological aspect to this acquired facial trauma which can be anxiety, depression, post-traumatic stress disorder, which adds to the morbidity of the facial trauma [18]

The type of helmet, the patient was wearing at the time of accident also influences the mortality [19]. The study shows that, full helmet decreases the mortality because of head injury and also protects the facial bones. There should be strict implementation of wearing helmets. The two wheeler riders do not strictly wear helmets, even among dental and medical students, only $28 \%$ of correspondents responded that they wear always helmets and $33 \%$ of the respondents never wore helmets [7].

There should be aggressive educational awareness for the use of helmets. Technology could be used in strict implementation of the helmet rule. To decrease the morbidities of facial bone fractures and mortality with head injuries, a study has proposed where in there is automatic detection of helmets so that the riders who try to escape the law will be persuaded to wear helmet strictly [20].

In our study, there was 10 cases documented, who were under the influence of alcohol, about $1.12 \%$ of cases. The head injury if associated with alcohol intoxication would be difficult to clinically differentiate between the two unless high we get a blood alcohol level. In many studies, $3.88 \%$ to $41.2 \%$ of patients have been found to be alcohol intoxicated [21,22]. 


\section{CONCLUSION}

Midface is the most common fracture in patients with road traffic accidents on two wheelers. Wearing of full helmets helps in decreasing the severity of these injuries. Awareness regarding use of full helmets should increase among the younger population.

\section{REFERENCES}

1- Ravikumar G, Manoharan, Sugapradha G R, "A Study on Faciomaxillary injuries in a tertiary care hospital”. Int surg J vol.4, no 8, pp 2450-2454,2017.

2- Zargar M, Khaji A, Karbakhsh M, Zarei MR, "Epidemiology study of facial injuries during a 13 month of trauma registry in Tehran. Indian J Med Sci vol 58, no 3, pp 109-14, 2004

3- MG Venugopal, R Sinha, PS Menon, PK Chattopadhyay, SK Chowdhury, "fractures in the maxillofacial region: A four year retrospective study". Med J Armed forces India vol 66, no 1,pp 14-17, 2010.

4- http://pibphoto.nic.in/documents/rlink/2016/jun/p20166905.pdf

5- http://www.who.int/mediacentre/factsheets/fs $358 /$ en/

6- $\quad$ Shirin Wadhwaniya, Shivam Gupta, Shailaja Tatali, Lakshmi K Josyula, Gopalkrishna Shirin Wadhwaniya, Shivam Gupta, Shailaja Tatali, Lakshmi K Josyula, Gopalkrishna
Gururaj, Adnan A Hyder, "The validity of self reported helmet use among motorcyclists in India". WHO South-East Asia journal of public health vol 4, no 1, 2015

7- Kalantharakath T, Iyer R, "Helmet attitudes and practices among university students of cental and medical professional courses in Vadodara, India". J Interdisipl Med Dent Sci vol3,pp180,2015

8- Hogg NJ, Stewart TC, Amstrong JE, Girotti MJ, "Epidemiology of maxillofacial injuries at trauma hospitals in Ontario, Canada, between 1992 and 1997". J Trauma vol 49 ,pp $425-432,2000$

9- Ashok K Gupta, Ramneesh Garg, Ashish Gupta, Kuljyit Baja, "A retrospective analysis of 189 patients of maxillofacial injuries presenting to atertiary care hospital in Punjab, of 189 patients of maxillofacial injuries presenting to atertiary care hospital in Punjab,
India". J Maxillofacial and oral Surg vol 8, no 3, pp 241-224,2009.

10- BR Chandrashekhar, CVK reddy, "A Five-year retrospective statistical analysis of maxillofacial injuries in patients admitted and treated at two hospitals of mysore city". Indian J of Dental Research vol 19, no 4, pp 304-308, 2008

11- Subhashraj K, Nanda Kumar N, Ravindran C, "Review of maxillofacial injuries in Chennai, India: a study of 2748 cases". Br J Oral Maxillofac Surg. Vol 45, no 8, pp $637-$ 639,2007

12- Prasad B Rajendra, Tony P Mathew, Amit Agarwal, Gagan Sabharawal, "Characteristics of associated craniofacial trauma in patients with head injuries: An experience with 100 cases". J Emerg Trauma Shock vol 2, no 2pp 89-94,2009

13- Hassan Momeni, Shirin Shahnaseri, Zeinab Hameheil, "Distribution assessment of maxillofacial fractures in trauma admitted patients in Yazd hospitals: an epidemiological study”. Dent Res J (Isfahan) vol 8, suppl 1, pp S80-S83,2011.

14- Pranav Kapoor, Namita Kalra "A retrospective analysis of maxillofacial injuries in patients reporting to a tertiary care hospital in East Delhi”'. Int J Crit Illn Inj Sci vol 2, no $1, \mathrm{pp} 6-10,2012$.

15- Kraus JF, Rice TM, Peek Asa C, McArthur DL, "Facial trauma and the risk of intracranial injury in motorcycle riders". Ann Emerg Med vol 41, no 1, pp 18-26, 2003.

16- Rajasekhar Gali, Sathya kumar deviredy, RV Kishore kumar, Sridhar Reddy Kanubaddy, Chaithanyaa Nemaly, Mohammed Akheel, "Faciomaxillary fractures in a semiurban south Indian teaching hospital: A retrospective analysis of 638 cases" .Contemp Clin Dent vol 6, no4, pp 539-543,2015.

17- K-Y Tham, E Seow, G Lau, "Pattern of injuries in helmeted motorcyclists in Singapore".Emerg Med J vol 21,pp 478-482,2004.

18- Avinash De Sousa, "Psychological issues in acquired facial trauma". Indian J Plast Surg. vol 43, no 2, pp 200-205,2015.

19- Yu WY, Chen CY, Chiu WT, Lin MR, "Effectiveness of different types of motorcycle helmets and effects of their improper use on head injuries". Int J Epidemiol vol 40, no 3, pp 794-803, 2011.

20- Maharsh Cesai, Shubham Khandelwal, Lokneesh Singh, Shilpa Gite , "Automatic helmet detection on public roads". IJETT vol 35, no 5, pp 185,2016.

21- Singh R, Singh HK, Gupta SC, Kumar Y, "Pattern, severity and circumstances of injuries sustained in road traffic accidents: a tertiary care hospital-based study". Indian J Community Med. Vol 39, pp 30-34, 2014.

22- Mohanavalli Singaram, Sree Vijayabala G, Rajesh Kumar Udhayakumar,"Prevalence. Pattern, etiology and management of maxillofacial trauma in a developing country: a retrospective study". J Korean Assoc Oral Maxillifac Surg vol 42, no 4, pp 174-181, 2016. 